\title{
Active learning in optics and photonics: experiences in Africa
}

\section{Alarcon, E. Arthurs, Z. Ben Lakhdar, I. Culaba, V. Lakshminarayanan, et al.}

M. Alarcon, E. Arthurs, Z. Ben Lakhdar, I. Culaba, V. Lakshminarayanan, J. Maquiling, A. Mazzolini, J. Niemela, D. Sokoloff, "Active learning in optics and photonics: experiences in Africa," Proc. SPIE 9664, Ninth International Topical Meeting on Education and Training in Optics and Photonics, 96641Y (24 October 2005); doi: 10.1117/12.2207699 and Photonics, 2005, Marseille, France 
Ref ETOP040

Active learning in optics and photonics : experiences in Africa

\author{
M. Alarcon ${ }^{1}$, E. Arthurs ${ }^{2}$, Z. Ben Lakhdar ${ }^{3}$, I. Culaba ${ }^{4}$, V. Lakshminarayanan ${ }^{5}$, J. Maquiling $^{4}$, A.

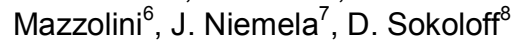

1. Division of Basic and Engineering Sciences, UNESCO, 1 rue Miollis, 75015 Paris, France

Tel. + 33 145.68.38.91; Fax +33 145.68.58.21; Email: m.alarcon@unesco.org

2. SPIE-The International Society for Optical Engineering, Bellingham, Washington, USA

3. University El Manar, Tunis, Tunisia

4. Ateneo de Manila University, Manila, The Philippines

5. University of Missouri, St. Louis, Missouri, USA

6. Swinburne Institute of Technology, Melbourne, Australia

7. Abdus Salam International Center for Theoretical Physics (ICTP), Trieste, Italy

8. University of Oregon, Eugene, Oregon, USA

\begin{abstract}
The UNESCO Active Learning in Optics and Photonics project is designed for the benefit of teachers of introductory university physics from developing countries. Initial implementation has taken place in two African nations, Ghana and Tunisia. The training curriculum includes student materials to teach topics in geometrical and physical optics in an active way with a high level of student involvement in the learning process. The curriculum makes use of simple, inexpensive materials. A conceptual learning assessment instrument is being developed as part of the project. Follow-up activities are planned. Experiences of the international group of workshop trainers are reported.
\end{abstract}

\title{
Keywords
}

active learning, Africa, optics, photonics, assessment, teacher training, developing countries, introductory university physics, conceptual learning

\section{Summary}

In its efforts to promote creativity and innovations in the way introductory physics is taught in the university, UNESCO has supported activities in different developing countries to address the need for teacher upgrading and introducing innovative learning approaches. In recent years, the focus in trainers' training workshops has been on the active learning approach, including developing teaching and learning materials. The focus of the Active Learning in Optics and Photonics project begun in 2003 and is based on one of the experimental physics areas that is relevant and adaptable to research and educational conditions in many developing countries. Optics has been termed an "enabling science" as it is believed to be the basis of many modern advances in high technology. This project is being developed for the benefit of university and senior high school physics teachers from developing countries and aims to train and better equip them to teach the optics part of the introductory physics course by using active learning with hands-on activities and by drawing examples from local research activities. Focusing on improving optics and photonics education will result in a viable and well-educated workforce for emerging industries in Africa where specific skills in this area will be needed. 
Active learning in physics, developed over the last decade, has been demonstrated in the United States and other developed countries to enhance student understanding of basic physics concepts. In this learning model, students are guided to construct their knowledge of physics concepts by direct observations of the physical world. Use is made of a learning cycle including predictions, small group discussions, observations and comparison of observed results with predictions. In this way, students become aware of the differences between the beliefs that they bring into the introductory physics classroom, and the actual physical laws that govern the physical world. An evolving product of many years of physics education research, the active learning method is known to measurably increase conceptual understanding. It reproduces the scientific process in the classroom and aids in the development of good physical reasoning skills.

The project is developing an activity-based teacher-training curriculum on the themes: Introduction to Light; Lenses and Optics of the Eye; Interference, Diffraction and Spectroscopy; Environmental Optics; and Optics in Communication. Modules with activities and appropriate instrumentation are being developed under each theme. Local fabrication of simple and inexpensive materials is being encouraged, and some distribution of simple materials has also taken place under the auspices of the project. An assessment instrument to measure student learning of optics concepts is being developed as part of the process. Follow-up activities are being designed to encourage teachers to implement the curriculum.

This project has been implemented by an international working group consisting of representatives from UNESCO, ICTP, SPIE, OSA and the Asian Physics Education Network (ASPEN). The authors of this paper make up the current working group that includes the team of resource persons who have prepared the training modules and have led the workshops. Physics teachers from developing countries are well represented in this group and there are plans to train more. Workshops are mainly funded by UNESCO with the support of ICTP and SPIE and recently, also from OSA. The budget for the project is very modest mainly because of the 'labor of love' contributed by the team of resource persons who volunteer their time and expertise to develop the modules and materials, and to travel around the world to present the workshops. The workshops are organized and hosted by local faculty and administrators. The host universities, like the Ateneo de Manila University (Philippines), University of Cape Coast (Ghana), and IPEIM at Monastir (Tunisia), have provided excellent technical and logistical support to help make the workshops successful.

Other active learning workshops have so far been organized in Ghana and Tunisia. Workshop participants were physics teachers from universities and senior high schools, including a number of department heads. Most participants had at least a first-degree in physics. There were a number with postgraduate degrees.

Both workshops began with the participants introducing themselves and the way they teach physics and optics in their respective classrooms. The participants in Ghana were from Nigeria, Benin, Togo and Ghana. We were impressed by their openness about the poor conditions under which they teach, often with large classes (up to 600 in some cases), absence of teaching materials and lack of teaching know-how. A number of participants had serious misunderstanding of some physical concepts. But the participants were very receptive to the 
active learning style, and participated enthusiastically in the activities. This is very important to the ultimate success of this project because in an active learning environment, the instructor becomes a guide and facilitator rather than the authority for all physics knowledge. As in the real scientific process, the physical world is the authority, and students learn from their observations of the world around them. We loved the way the Ghana participants would argue about physics explanations for the various observations in a friendly and constructive manner with their colleagues and facilitators, and felt they would have little difficulty encouraging their students to do the same.

The participants in Tunisia were from Algeria, Morocco, Ethiopia, Cameroon, South Africa and Tunisia. They were all very enthusiastic, open to new ideas, and easily worked together in groups, irrespective of their national origin, religion, and biases. They really wanted to learn and did not have a mental block in accepting a new approach. In both Ghana and Tunisia, the teachers were very enthusiastic about learning new teaching methods and making themselves better teachers. Through the workshops, the teachers realized that local fabrication of materials does work, and activities can be effectively done without expensive instruments. In Tunisia, we even had a brief session on how to fabricate the teaching materials used in the workshop, including some instruction and practice time on soldering simple circuits.

In both countries, the participants worked very hard during the sessions and demonstrated a strong desire to learn. It is this combination of willingness to learn and conscientiousness that makes presenting these workshops so satisfying to the workshop team. One clearly senses that these participants wish to serve their students better, and that given any opportunity, they will try to implement the methods to which they have been exposed in the active learning workshops.

These workshops expose teachers from developing countries to new ideas in physics teaching that have been developed in response to many years of physics education research. They can refresh their understanding of physics concepts and get the opportunity to interact with educational experts from developed and developing countries. The active learning method will help in developing the types of physical reasoning skills needed for doing active and productive research that can help to sustain growth and strength in the academic sector and in emerging industries. The workshops provide a venue for teaching and learning to take place, adapted to the local environment, and allow teachers from different countries to work together without barriers. The science and the teaching methods are truly international and have the capacity to bring people closer together in both a professional and personal way. 